\title{
COMPLEX PATTERNS IN L1-TO-L2 PHONETIC TRANSFER: \\ THE ACQUISITION OF ENGLISH PLOSIVE AND AFFRICATE FAKE GEMINATES AND NON- HOMORGANIC CLUSTERS BY POLISH LEARNERS ${ }^{1}$
}

\author{
ANDRZEJ PORZUCZEK \\ University of Silesia, Katowice, Poland \\ andrzej.porzuczek@us.edu.pl
}

\author{
ARKADIUSZ ROJCZYK \\ University of Silesia, Katowice, Poland \\ arkadiusz.rojczyk@us.edu.pl
}

\begin{abstract}
This paper analyses the way that Polish learners of English articulate plosive and affricate consonants preceding another obstruent occlusive in both L1 and L2. Considering that English allows unreleased plosives before any stop, that is in a wider range of contexts than Polish, a Polish learner may find it confusing that it is regarded unacceptable to block the affricate release before another (in English always homorganic) affricate. In Polish the first of two homorganic affricates is often reduced to the occlusion phase, while unreleased plosives appear very rarely in non-homorganic contexts. This apparent paradox in the treatment of affricate and plosive consonant clusters may lead to complicated transfer patterns, which we examine by observing the release suppression tendencies in Polish and English phrases and sentences read by phonetically trained and untrained Polish learners of English. The results indicate strong negative transfer tendencies and suggest a connection between gemination patterns and unreleased occlusive distribution in a language.
\end{abstract}

Keywords: L2 speech, phonetic transfer, unreleased stops, geminates

\section{Introduction}

The occurrence of positional allophones in world's languages, besides specific phonological functions, is often motivated by articulation economy. Numerous effects of interactions between neighbouring phonemes are universal and thus naturally expected in human speech. However, not all languages allow the same variety of possible effort-saving phonetic processes and, in foreign language

\footnotetext{
${ }^{1}$ Research supported by the National Science Centre Poland grant Acoustic properties of Polish geminate consonants UMO-2017/25/B/HS2/02548
} 
learning, the resulting asymmetry between L1 and L2 offers a major challenge to the learner. Table 1 presents phonetic and phonological processes appearing asymmetrically in the realization of English and Polish plosives.

Table 1: Processes in plosive consonant realizations in English and Polish

\begin{tabular}{|c|c|c|}
\hline process & English & Polish \\
\hline aspiration & YES & NO \\
\hline pre-fortis clipping & YES & NO \\
\hline no release & YES & LIMITED \\
\hline nasal release & YES & LIMITED \\
\hline gemination & ONLY FAKE & TRUE AND FAKE \\
\hline
\end{tabular}

If we focus on the problem of stop release suppression, labelled "limited" in Table 1 for Polish, it turns out that the process, allowed before occlusive obstruents and in the word-final position in English (e.g. Jones 1956, Abercrombie 1967, Ladefoged 1975, Roach 2000, Cruttenden 2001) is restricted to homorganic stop combinations in Polish (Jassem 1974, Kopczyński 1977, Wierzchowska 1980, Dukiewicz and Sawicka 1995, Rojczyk 2008). The process, if allowed, appears both within words and across a word boundary (as illustrated in Table 2) in both languages.

Table 2: Unreleased plosive distribution in English and Polish

\begin{tabular}{|c|c|c|}
\hline position & English & Polish \\
\hline pre-stop homorganic & that time & $\begin{array}{c}\text { lot taty } \\
\text { netto } \\
\text { przedtem } \\
\text { kod Dawida }\end{array}$ \\
\hline $\begin{array}{c}\text { pre-stop heterorganic } \\
\text { (assimilation possible) }\end{array}$ & $\begin{array}{c}\text { picture } \\
\text { doctor } \\
\text { football } \\
\text { hot cheese }\end{array}$ & ----- \\
\hline word-final & Do it. & ----- \\
\hline
\end{tabular}

Additionally, an English pre-stop alveolar plosive may adopt the place of articulation of the following consonant, thus showing a tendency to increase the proportion of homorganic clusters, even though this is not required to suppress the release of the first element. Such assimilation is possible in Polish only within the range of coronal sounds, which means, for example, that a dental /d/ or $/ t /$ is never transformed into a labial or a velar.

The tendency, however, seems to be reversed in the case of affricates. This time it is Polish that allows unreleased realization of such a consonant before another affricate, especially a homorganic one (Thurgood 2001). Table 3 shows 
examples of Polish affricate combinations where the first element can be pronounced without a plosion.

Table 3: Polish homorganic affricate combinations

\begin{tabular}{|c|c|c|}
\hline word/phrase & $\begin{array}{c}\text { affricate } \\
\text { combination }\end{array}$ & meaning \\
\hline uczczą & $\mathfrak{y t g}^{2}$ & they will celebrate \\
\hline idźcie & tctc & go! \\
\hline pizza & tsts & pizza \\
\hline płacz czapli & $\mathfrak{t} \# \mathfrak{t}$ & heron's cry \\
\hline zadać cios & tc\#tt & to deal a blow \\
\hline koc Celiny & ts\#ts & Celina's blanket \\
\hline
\end{tabular}

English pronunciation textbooks unanimously state that an English affricate must not be pronounced without the release phase, even before stops (e.g. Cruttenden 2001: 177, Gómez González and Sánchez-Roura 2016: 206, Carley and Mees 2018: 22). Considering the asymmetry between the languages in forming pre-stop allophones of plosives and affricates, we may expect that Polish learners, as a result of negative transfer, will use too many plosive bursts in English speech ('actor,' 'hot pies,' 'picture') on the one hand, and at least some unreleased affricates ('much cheaper,' 'orange juice') on the other. These pronunciation problems are particularly frustrating and confusing since the learner is faced with two new and apparently contradictory articulation patterns to follow.

\section{The study design}

The objective of our study is to investigate how serious the predicted problem is in real EFL learning situation. We pose the following research questions:

1. To what extent do Polish speakers use unreleased occlusives in monitored L1 and EFL production?

2. Do they transfer Polish patterns (preference for unreleased homorganic plosives and affricates) into English speech?

3. Do the transfer tendencies depend on EFL learning experience?

A major difficulty in the study is that although the process is considered natural in English speech and pronunciation textbooks even provide exercises in unreleased plosives, it is not obligatory, and various factors such as speaking style,

${ }^{2}$ For better clarity of cross-language comparisons, we use the symbol / $\mathrm{t} /$ instead of $/ \mathrm{ts} /$ to indicate the Polish postalveolar affricate. 
tempo, level of discourse formality, etc. may trigger the consonant release also in native speech. This is evident in the results of a number of studies, e.g. Crystal and House (1988), Byrd (1993), and even Davidson (2010) who analysed the spontaneous speech recorded in National Public Radio database. All these researchers found over $40 \%$ of plosives in their data to be released in the contexts in question. Apart from these studies, we have not found other research investigating the topic.

\subsection{Participants}

Thirty-six native speakers of Polish (thirty-one females and five males) participated in the study. They ranged in age from 19 to 22. All participants were English studies majors at the Institute of English, University of Silesia. Fourteen of them (first-year students) had had no prior phonetic training in English phonetics, while the remaining twenty-two (second-year students) had completed a two-semester course in practical English phonetics including the pronunciation of English consonants' positional variants. None of the participants reported any speech or hearing disorders.

\subsection{Stimuli}

In order to elicit comparable L1 and L2 speech samples, we prepared a list of phrases with the two occlusive consonants neighbouring across a word boundary. The absence of geminates in English precluded the use of single words as stimuli testing homorganic combinations. Because the use of all possible plosive/affricate combinations would produce a large number of tokens and thus adversely influence the subjects' performance, we focused on coronal occlusives, as there are no peripheral affricates in English. Despite some slight differences in the places of articulation of Polish and English $/ \mathrm{t} /$ and $/ \mathrm{t} /$, they can be regarded as close phonological cross-linguistic counterparts.

All Polish and English occlusives appear in phonologically contrasting voicedvoiceless pairs but we only included the voiceless segments in order to avoid possible variation in the voicing of the word final consonant $(\mathrm{C} 1)$, even in a phrase-medial position. To test non-homorganic combinations, we used wordinitial $/ \mathrm{p} /$ in the second element of the phrase $(\mathrm{C} 2)$, so that the second occlusion was more advanced than the first one. A reverse combination, where the second occlusion is retracted with respect to the first one, is more often articulated with an exploded $\mathrm{C} 1$.

All the phrases in both languages were combinations of a monosyllable and a trochaic word. This allowed us to control for the influence of varying prominence distribution on the articulation of consonants. The English phrases were composed of a quantifier and the comparative form of an adjective, while the Polish ones 
consisted of a head noun followed by another noun ${ }^{3}$ in the possessive (genitive) form. This was to ensure a maximum level of similarity of the phonological structures, stress patterns and collocation strength. Polish expressions additionally included combinations with the other two voiceless affricates. The test phrases are presented in Table 4.

Table 4: Stimuli

\begin{tabular}{|c|c|c|}
\hline $\begin{array}{c}\text { stop combination } \\
(\mathbf{C 1 \# C 2})\end{array}$ & ENG & POL \\
\hline$/ \mathrm{t \# t/}$ & lot taller & lot tani (cheap flight) \\
\hline$/ \mathrm{t \# p/}$ & lot poorer & lot pawia (peacock's flight) \\
\hline$/ \mathrm{t \# t} / /$ & lot cheaper & lot czapli (heron's flight) \\
\hline$/ \mathrm{t} / \# \mathrm{t} /$ & much taller & płacz taty (dad's cry) \\
\hline$/ \mathrm{t} / \mathrm{t} \mathrm{t} /$ & much cheaper & $\begin{array}{c}\text { płacz czapli (heron's cry) } \\
\text { moc ceny (price power) } \\
\text { mieć ciastko (to have a cake) } \\
\text { grać czysto (play fair) }\end{array}$ \\
\hline$/ \mathrm{t} \# \mathrm{t} / \mathrm{t} / \mathrm{t} / \mathrm{t} /$ & & \multicolumn{2}{|c}{} \\
\hline
\end{tabular}

Considering that the experiment was to be carried out in laboratory conditions, which typically lead to slower, more careful and distinct speech, including more released occlusive consonants, we placed the phrases in the following carrier sentences, ensuring uniform rhythmic and semantic patterns. Each sentence was concluded by a trochaic word in order not to leave the tested words in a sentencefinal position:

English: I know it is [much] ...., Kelly OR I know it's a [lot]....., Kelly. Polish: Ja wiem, co znaczy ...., babciu. (I know what ...... means, Grandma) ${ }^{4}$

\subsection{Procedure}

The recordings took place in the Acoustic Laboratory, Institute of English, University of Silesia in a sound-proof booth, using a condenser microphone Shure PGA27, preamplified by Steinberg UR44 (Yamaha). The signal was captured at $48 \mathrm{kHz}$ with sampling of $24 \mathrm{bit}$.

The task was to read the two-word test phrases first in isolation (citation forms) and then in carrier phrases (connected speech). The English stimuli were presented to the participants before the Polish ones, and the citation forms preceded connected speech (phrases before sentences).

\footnotetext{
${ }^{3}$ The last two affricate combinations consisted of an infinitive and a noun, and an infinitive followed by an adverb. All these combinations formed rhythmically comparable structures.

${ }^{4}$ The original Polish word order is *'I know what means...., Grandma.'
} 
To further enhance more fluent articulation, the participants were instructed to read each example three times, using their natural speaking tempo. They were also asked to repeat a phrase or a sentence in the case of any disfluencies.

\subsection{Data collection}

For analysis, we selected the third repetition of each token. This material was then analysed using PRAAT software (Boersma 2001), by means of visual and auditory recording inspection for presence or absence of $\mathrm{C} 1$ release.

\section{Results and analyses}

In this section we present the general observations made in the process of data collection (3.1), the basic descriptive statistics (3.2), and detailed statistical analysis of the data (3.3).

\subsection{General observations}

While analyzing the gathered data, we observed, as we had expected, that in laboratory conditions the speakers mostly released $\mathrm{C} 1$, especially in citation forms (phrases). An unexpected finding was a strikingly higher number of unreleased plosives and affricates in English examples, which we are going to discuss in more detail later. Furthermore, unreleased affricates were hardly less frequent than unreleased plosives, which is illustrated in Figure 1 (top), and non-homorganic pre-stop plosives were practically always released, as shown in Fig.1 (bottom). 


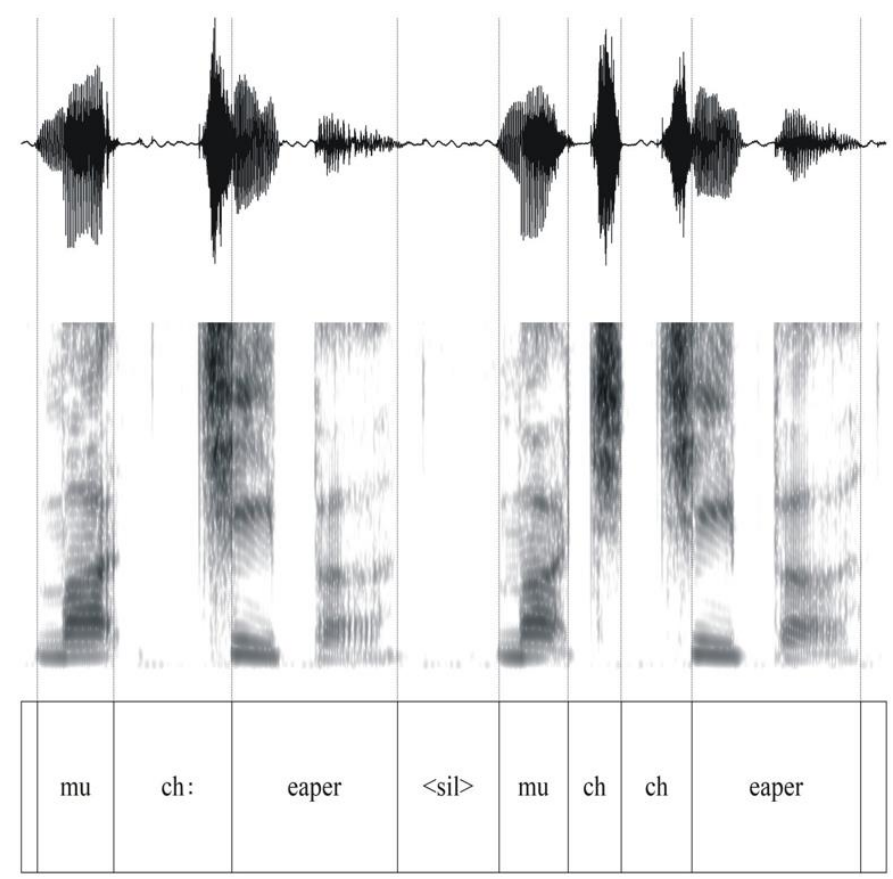

Figure 1: Two typical realizations of $/ \mathrm{f} \# \mathrm{~g} / \mathrm{in}$ 'much cheaper' by a Polish

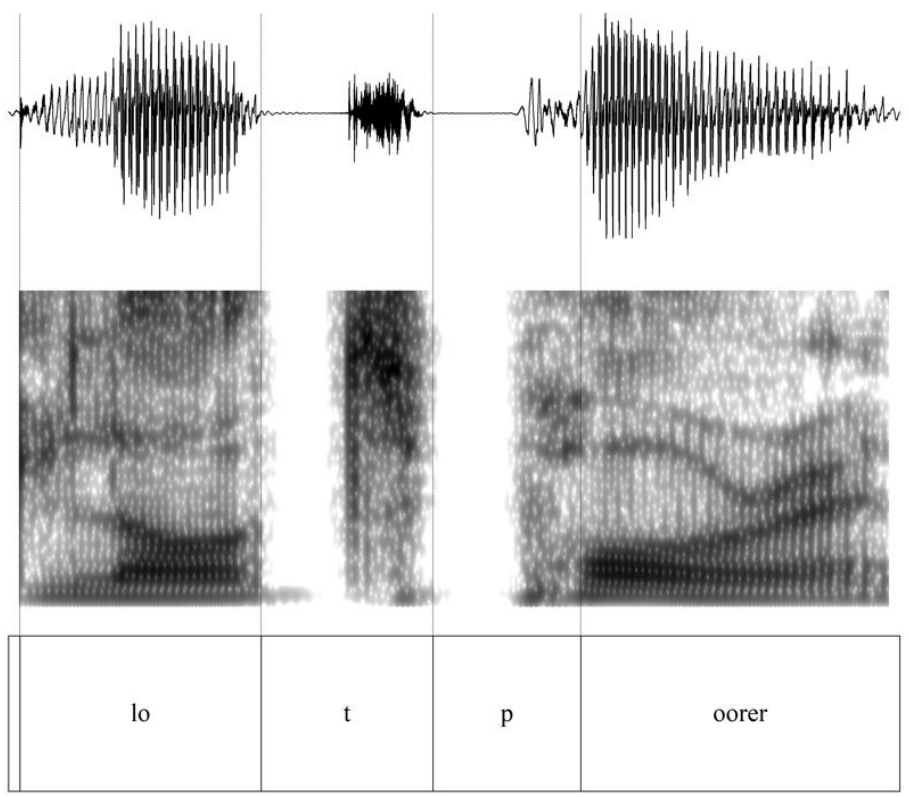

Figure 2: A typical realization of /t\#p/ in 'lot poorer' by a Polish learner 
Non-homorganic pre-stop plosives, on the other hand, were practically always released, which is illustrated by Figure 2

Figure 1 and Figure 2 show the most typical realizations of the two combinations, but we have generally observed considerable variation across languages, contexts and speaking styles, which requires a more detailed analysis.

\subsection{General results}

Unreleased articulation of stops is typical of spontaneous speech but in monitored speech it is often avoided. The general results presented in Table $5^{5}$ show only incidental cases of unreleased stops in Polish phrases. In larger contexts (sentences) the rate rises to a 15-30\% proportion, depending on the phonological environment. As we have mentioned before, the participants resorted to unreleased articulation of $\mathrm{C} 1$ approximately three times more often in English than they did in Polish examples.

Table 5: Overall number and proportion of unreleased plosives and affricates

\begin{tabular}{|l|cc|cc|cc|cc|cc|cc|cc|}
\hline N=36 & tt & $\mathbf{\%}$ & tp & $\mathbf{\%}$ & tt & $\mathbf{\%}$ & tff & $\mathbf{\%}$ & tst & $\mathbf{\%}$ & tct6 & $\mathbf{\%}$ & ttf & $\mathbf{\%}$ \\
\hline POL phrase & 1 & $\mathbf{3}$ & 0 & $\mathbf{0}$ & 5 & $\mathbf{1 4}$ & 2 & $\mathbf{6}$ & 0 & $\mathbf{0}$ & 4 & $\mathbf{1 1}$ & 3 & $\mathbf{8}$ \\
\hline POL sentence & 6 & $\mathbf{1 7}$ & 3 & $\mathbf{8}$ & 6 & $\mathbf{1 7}$ & 6 & $\mathbf{1 7}$ & 8 & $\mathbf{2 2}$ & 10 & $\mathbf{2 8}$ & 9 & $\mathbf{2 5}$ \\
\hline ENG phrase & 19 & $\mathbf{5 3}$ & 4 & $\mathbf{1 1}$ & 18 & $\mathbf{5 0}$ & 12 & $\mathbf{3 3}$ & & & & & & \\
\hline ENG sentence & 22 & $\mathbf{6 1}$ & 9 & $\mathbf{2 5}$ & 19 & $\mathbf{5 3}$ & 17 & $\mathbf{4 7}$ & & & & & & \\
\hline
\end{tabular}

We naturally expected that second-year students should produce more unreleased consonants in English than the first-year students, but the general results, as shown in Table 6, do not confirm our prediction.

Table 6: Overall number and proportion of unreleased plosives and affricates.

Between-group comparison

\begin{tabular}{|l|cc|cc|cc|cc|cc|cc|cc|}
\hline 1st year N=14 & $\mathrm{tt}$ & $\mathbf{\%}$ & $\mathrm{tp}$ & $\mathbf{\%}$ & $\mathrm{tt}$ & $\mathbf{\%}$ & $\mathrm{tff}$ & $\mathbf{\%}$ & $\mathrm{tst}$ & $\mathbf{\%}$ & $\mathrm{tct}$ & $\mathbf{\%}$ & $\mathrm{tct}$ & $\mathbf{\%}$ \\
\hline POL phrase & 1 & $\mathbf{7}$ & 0 & $\mathbf{0}$ & 2 & $\mathbf{1 4}$ & 1 & $\mathbf{7}$ & 0 & $\mathbf{0}$ & 2 & $\mathbf{1 4}$ & 1 & $\mathbf{7}$ \\
\hline POL sentence & 4 & $\mathbf{2 9}$ & 1 & $\mathbf{7}$ & 3 & $\mathbf{2 1}$ & 3 & $\mathbf{2 1}$ & 4 & $\mathbf{2 9}$ & 5 & $\mathbf{3 6}$ & 5 & $\mathbf{3 6}$ \\
\hline ENG phrase & 10 & $\mathbf{7 1}$ & 3 & $\mathbf{2 1}$ & 7 & $\mathbf{5 0}$ & 4 & $\mathbf{2 9}$ & & & & & & \\
\hline ENG sentence & 10 & $\mathbf{7 1}$ & 4 & $\mathbf{2 9}$ & 10 & $\mathbf{7 1}$ & 6 & $\mathbf{4 3}$ & & & & & \\
\hline
\end{tabular}

\begin{tabular}{|l|cc|cc|cc|cc|cc|cc|cc|}
\hline 2nd year N=22 & tt & $\boldsymbol{\%}$ & tp & $\boldsymbol{\%}$ & tf & $\mathbf{\%}$ & tf & $\mathbf{\%}$ & tst & $\boldsymbol{\%}$ & tet6 & \% & tct & \% \\
\hline POL phrase & 0 & $\mathbf{0}$ & 0 & $\mathbf{0}$ & 3 & $\mathbf{1 4}$ & 1 & $\mathbf{5}$ & 0 & $\mathbf{0}$ & 2 & $\mathbf{9}$ & 2 & $\mathbf{9}$ \\
\hline POL sentence & 2 & $\mathbf{9}$ & 2 & $\mathbf{9}$ & 3 & $\mathbf{1 4}$ & 3 & $\mathbf{1 4}$ & 4 & $\mathbf{1 8}$ & 5 & $\mathbf{2 3}$ & 4 & $\mathbf{1 8}$ \\
\hline ENG phrase & 9 & $\mathbf{4 1}$ & 1 & $\mathbf{5}$ & 11 & $\mathbf{5 0}$ & 8 & $\mathbf{3 6}$ & & & & & & \\
\hline ENG sentence & 12 & $\mathbf{5 5}$ & 5 & $\mathbf{2 3}$ & 9 & $\mathbf{4 1}$ & 11 & $\mathbf{5 0}$ & & & & & \\
\hline
\end{tabular}

\footnotetext{
${ }^{5}$ Apart from $/ \mathfrak{f} \mathrm{f} /$, we also include the other homorganic and non-homorganic Polish affricate combinations: /sts/, /tetc/ and /tty/, which allows us to collect more data illustrating the occurrence of unreleased affricates in Polish.
} 
The data presented in Table 5 and Table 6 are further analyzed statistically in the section that follows.

\subsection{Statistical model}

Given the type of our data, we decided to use the Chi-square test to perform the relevant analyses. We use the terms 'between-group' and 'within-group' to indicate whether the dependent variables were collected from separate participant groups (1st vs $2^{\text {nd }}$ year) or whether they were pooled together for both groups.

\subsubsection{Between-group comparison}

The between-group (1st vs 2 nd year) comparison was performed using Chi-square corrected for sample size with V-square. We obtained the following statistical results for unreleased realizations in the tested combinations:

Table 7: Between-group $\left(1^{\text {st }}\right.$ vs $2^{\text {nd }}$ year $)$ comparisons

\begin{tabular}{|c|c|c|}
\hline $\begin{array}{c}\text { stop combination } \\
(\mathrm{C} 1 \# \mathrm{C} 2)\end{array}$ & $\begin{array}{c}\mathrm{ENG} \\
\chi^{2}(1)\end{array}$ & $\begin{array}{c}\text { POL } \\
\chi^{2}(1)\end{array}$ \\
\hline$/ \mathrm{t \# t} /$ & $3.87, \mathrm{p}=.049$ & $3.41, \mathrm{p}=.065$ \\
\hline$/ \mathrm{t \# p} /$ & $1.47, \mathrm{p}=.225$ & $.04, \mathrm{p}=.841$ \\
\hline$/ \mathrm{t} \# \mathrm{~g} /$ & $1.14, \mathrm{p}=.286$ & $.23, \mathrm{p}=.63$ \\
\hline$/ \mathrm{t} \# \mathrm{~g} /$ & $.39, \mathrm{p}=.532$ & $.46, \mathrm{p}=.497$ \\
\hline$/ \mathrm{f} \# \mathrm{t} /$ & - & - \\
\hline
\end{tabular}

There were no significant between-group differences for any of the tested sequences. Therefore, we decided to pool the data together, which made it possible to perform the other analyses on a larger sample.

\subsubsection{Within-group comparison: Polish vs English}

The raw data presented in Table 5 indicated surprisingly higher rates of unreleased stops in the English production of the participants. The statistics showing the effect of language with respect to particular consonant combinations were calculated using McNemar Chi-square for dependent samples. We obtained the following results based on the rates of unreleased realizations:

a) homorganic plosives $/ \mathrm{t} \# \mathrm{t} /: \chi^{2}(1)=22.69, \mathrm{p}<.001 * *$

b) non-homorganic plosives $/ \mathrm{t} \# \mathrm{p} /: \chi^{2}(1)=5.06, \mathrm{p}=.025^{*}$

c) plosive+affricate $/ \mathrm{t} \# \mathrm{t} \mathrm{f} / \chi^{2}(1)=13.02, \mathrm{p}<.001 * *$

d) homorganic affricates $/ \mathrm{t} \mathrm{f} \# \mathrm{t} \mathrm{f} / \mathrm{\chi} \chi^{2}(1)=10.81, \mathrm{p}=.001 * *$

e) affricate+plosive $/ \mathrm{t} \mathrm{f} \# \mathrm{t} / \mathrm{-}$ no unreleased affricates

All differences between Polish and English samples were highly significant statistically, with the exception of non-homorganic plosives / $\mathrm{t} \# \mathrm{p} /$, typically both released in Polish, where the difference was only moderately significant. 


\subsubsection{Within-group comparison: phonological context status}

Bearing in mind potential interference problems, we grouped the data in Table 8 below according to the eligibility of unreleased occlusives for a given context in both languages. A plus or a minus next to a language label indicates whether the occurrence of an unreleased variant is allowed (+) or forbidden (-) in a given combination.

Table 8: Unreleased occlusives in "allowed" and "forbidden" combinations

\begin{tabular}{|c|l|c|c|}
\hline $\begin{array}{c}\text { combination } \\
\text { status }\end{array}$ & \multicolumn{1}{|c|}{ tested samples } & $\begin{array}{c}\text { frequency in } \\
\text { POL }\end{array}$ & $\begin{array}{c}\text { frequency in } \\
\text { ENG }\end{array}$ \\
\hline POL+, ENG+ & $\begin{array}{l}\text { homorganic pre-stop plosives /t\#t/, } \\
\text { /t\#t } /\end{array}$ & $13 \%$ & $54 \%$ \\
\hline POL+, ENG- & homorganic affricates $/ \mathrm{t} \mathrm{f} \mathrm{t} \mathrm{f} / \mathrm{t}$ & $11 \%$ & $40 \%$ \\
\hline POL-, ENG+ & non-homorganic plosives $/ \mathrm{t} \# \mathrm{p} /$ & $4 \%$ & $18 \%$ \\
\hline POL-, ENG- & pre-stop affricate $/ \mathrm{t} \mathrm{f} \# \mathrm{t} /$ & $0 \%$ & $0 \%$ \\
\hline
\end{tabular}

We also applied McNemar Chi-square for dependent samples to assess the discrepancies between the rates of unreleased realizations in English, which obviously confirmed the statistical significance of the differences, but also showed Polish speakers' tendency to use more unreleased occlusives in "POL+, ENG-" than "POL-, ENG+" contexts:

a) [POL+, ENG+] (homorganic plosives /t\#t//t\#t/) vs [POL-, ENG+] (heterorganic plosives $/ \mathrm{t} \# \mathrm{p} /$ ): $\chi^{2}(1)=45.01, \mathrm{p}<.001 * *$

b) [POL+, ENG+] (homorganic plosives /t\#t//t\#t $/$ /) vs [POL+, ENG-] (homorganic affricates $/ \mathrm{t} \mathrm{f} \# \mathrm{t} /$ ) $: \chi^{2}(1)=21.53, \mathrm{p}<.001 * *$

c) [POL-, ENG+] (heterorganic plosives /t\#p/) vs [POL+, ENG-] (homorganic affricates $/ \mathrm{t} f \# \mathrm{t} / \mathrm{f}): \chi^{2}(1)=5.36, \mathrm{p}=.021^{*}$

\subsubsection{Within-group comparison: phrases vs. sentences}

Finally, we measured the effect of speaking style/tempo on the frequency of occurrence of unreleased occlusives, again using McNemar Chi-square for dependent samples. It turned out that a moderately significant difference appeared between the data calculated for all contexts, with $21 \%$ and $31 \%$ of unreleased occlusives in phrases and sentences, respectively $\left(\chi 2(1)=4.54, p=.033^{*}\right)$. For individual contexts, the differences proved to be non-significant.

\section{Discussion}

Even though the participants tended to use released plosives in Polish far more frequently, the general results for English phrases and sentences are in line with previous research, with over a half of the plosives unreleased in contexts where 
the process is allowed in both Polish and English. In these contexts we have also observed a moderately higher rate of unreleased plosives in sentences $(57 \%)$ than in phrases $(51 \%)$.

The frequency of unreleased occlusives in Polish learners' English speech appears to depend mostly on L1 phonetic principles. This is indicated by a considerably higher rate of suppressed release in "POL+, ENG-" contexts (40\%) than in "POL-, ENG+" ones (18\%).

Contrary to our expectations, Polish learners used far more unreleased plosives in the foreign language than in their native language. This could have been caused by two factors, each of which would need to be tested in separate further studies. The first possible reason is a difference in attitudes to language norm. Outside the context of natural communication, Polish learners may feel more pressure for clear L1 speech, which they may have experienced at previous education stages. English, on the other hand, may be perceived as a language with less focus on distinct articulation of individual sounds, and learners are often explicitly encouraged by teachers to employ processes that make their speech more fluent, such as various kinds of assimilations, elision, etc. The other reason, probably a more likely one, is a difference in the collocation strength of our tested phrases. The English examples were based on more fixed phrases with 'a lot' and 'much' followed by the comparative form of an adjective. In order to make the corresponding Polish stimuli phonologically comparable, we used phrases which may have turned out to be more marked and characterized by weaker collocation bonds. The process apparently being sensitive to such factors, the results revealed fewer unreleased consonants. This unexpected finding does not affect the results that we have obtained with respect to L2 English pronunciation of Polish learners but we consider it worthy of further investigation.

Another interesting question is why the two languages differ in the treatment of plosives and affricates. In our opinion, future research may be directed towards the phenomenon of gemination. We hypothesize that Polish allows not only unreleased plosives but also unreleased affricates because it is a geminating language. In most geminating languages, prolonged duration of a segment is the main cue to a geminate. In the case of stop geminates, including affricates, it is typically the occlusion phase that is prolonged, while rearticulation with two consecutive released closures is rather rare. Polish does allow double articulation of stop geminates, but increased duration of the occlusion still remains the principal realization. Then the articulation of true (morpheme-internal) geminates may be extended to fake (cross-boundary) ones. This interpretation may also explain why unreleased stops are not allowed in Polish except in what can be considered a true or fake geminate. In English, on the other hand, it is acceptable to pronounce plosives using only the occlusion gesture, and even the place of articulation (save most pre-vocalic positions) need not be preserved. Affricates, however, must be released properly since the frication phase is indispensable for consonant identification. The missing frication phase may not be justified by the geminate status of a two-affricate combination either, as geminates are not 
allowed in English. This tentative hypothesis would obviously require further investigation.

\section{Conclusions}

The main conclusions that we draw from the present research refer to two aspects of the investigated problem, i.e. the distinct phonological properties of plosives and affricates in English and Polish in terms of geminate formation, and the crosslinguistic interactions in the production of L1 and L2 consonant clusters. Our data suggest that the apparent internal inconsistency in stop cluster realizations in the two languages reflects their dissimilar constraints which forbid geminate formation in English and stop release suppression in Polish, the latter being allowed in true and fake geminates alone.

The above conclusion forms a tentative explanation for the observed tendencies in the realization of stop combinations in English and Polish by native Polish speakers. These tendencies include a preference (72-83\% of cases) for the release of pre-stop homorganic plosives and affricates in Polish sentences. The release was only sporadically suppressed in short phrases. On the other hand, the learners produced no plosion in approximately 50-60\% of English phrases and sentences in the most propitious context, i.e. the pre-stop homorganic position, which allows release suppression in both languages. Furthermore, a considerable proportion tend to transfer their L1 occlusion release patterns to their L2 speech, with $33-47 \%$ unreleased affricates and $75-89 \%$ released pre-stop heterorganic plosives. The discrepancy between plosives and affricates indicates the prevalence of the English constraint in a number of learners.

Finally, we observe that release suppression regarded as an effort-saving articulatory process, inhibited to varying degrees by language-specific phonological constraints, is enhanced by typical factors determining the final phonetic outcome, such as speaking tempo and style, word or collocation frequency. The actual influence of these factors needs further empirical evidence. Given the present data, we conclude that in the L2 learning context, L1 patterns tend to prevail in both language productions. Moreover, this preference does not change with growing L2 experience.

\section{Acknowledgements}

Research supported by the National Science Centre Poland grant Acoustic properties of Polish geminate consonants (UMO-2017/25/B/HS2/02548).

\section{References}

Abercrombie, David. 1967. Elements of General Phonetics. Edinburgh: Edinburgh University Press. 
Bałutowa, Bronisława. 1974. Wymowa angielska dla wszystkich. Warszawa: Wiedza Powszechna.

Boersma, Paul. 2001. Praat, a system for doing phonetics by computer. Glot International 10: 341345.

Byrd, Dani. 1993. 54,000 American stops. UCLA Working Papers in Phonetics 83: 1-19.

Crystal, Thomas H. and Arthur S. House. 1988. The duration of American-English stop consonants. Journal of Phonetics 16: 285-294.

Carley, Paul and Mees, Inger M. 2020. American English Phonetics and Pronunciation Practice. London \& New York: Routledge.

Cruttenden, Alan. 2001. Gimson's Pronunciation of English. London \& New York: Routledge.

Davidson, Lisa. 2010. Variation in stop releases in American English spontaneous speech. Journal of the Acoustical Society of America 128: 2458.

Dukiewicz, Leokadia and Irena Sawicka. 1995. Fonetyka i fonologia. In H. Wróbel (ed.) Gramatyka i fonologia języka polskiego. Kraków: Instytut Języka Polskiego PAN.

Gómez González, María de los Ángeles and Teresa Sánchez Roura. 2016. English Pronunciation for Speakers of Spanish: From Theory to Practice. Boston/Berlin: Walter de Gruyter.

Jones, Daniel. 1956. An Outline of English Phonetics. Cambridge: Heffer and Sons.

Jassem, Wiktor. 1974. Fonetyka języka angielskiego. 4th edition. Warszawa: PWN.

Kopczyński, Andrzej. 1977. Polish and American English Consonant Phonemes. Warszawa: PWN.

Ladefoged, Peter. 1975. A Course in Phonetics. Orlando: Harcourt Brace.

Roach, Peter. 2000. English Phonetics and Phonology. 3rd edition. Cambridge: Cambridge University Press.

Rojczyk, Arkadiusz. 2008. Release burst in Polish homorganic stop geminates. Linguistica Silesiana 29: 75-86.

Thurgood, Ela. 2001. The phonetic realizations of phonologically geminate affricates in Polish: The Long and the Short of it. Speech and Language Technology 5: 9-19.

Wierzchowska, Bożena. 1980. Fonetyka i fonologia języka polskiego. Wrocław: PAN. 